\title{
Is Early Treatment with a Cervical Pessary an Option in Patients with a History of Surgical Conisation and a Short Cervix?
}

\author{
Ist die frühe Behandlung mit einem zervikalen Pessar eine Option \\ für Patientinnen nach Konisation und Zervixverkürzung?
}

Authors

Affiliation
I. Kyvernitakis, R. Khatib, N. Stricker, B. Arabin

Department of Gynecology and Obstetrics, Philipps-University of Marburg, Marburg in cooperation with the Clara Angela Foundation, Witten

\author{
Key words \\ - conisation \\ - pessary \\ - cerclage \\ - cervical shortening \\ - preterm birth \\ Schlüsselwörter \\ - Konisation \\ - Pessar \\ - Cerclage \\ - Zervixverkürzung \\ - Frühgeburt
}

\section{received $\quad 7.9 .2014$ \\ revised 20.10.2014 \\ accepted 26.10.2014}

\section{Bibliography}

DOI http://dx.doi.org/

10.1055/s-0034-1383271

Geburtsh Frauenheilk 2014; 74

1003-1008 ๑ Georg Thieme

Verlag KG Stuttgart · New York .

ISSN 0016-5751

\section{Correspondence}

\section{Dr. loannis Kyvernitakis, MD}

Philipps-University of Marburg

Department of Gynecology

and Obstetrics

Baldingerstraße 1

35033 Marburg

kyvernit@med.uni-marburg.de

\section{Abstract \\ $\nabla$}

Objective: Patients with a history of one or more conizations have an increased risk of spontaneous preterm birth (SPTB). The aim of this study was to investigate the outcome of pregnancies in patients with a history of conization and early treatment with a cervical pessary.

Methods: In this pilot observational study we included 21 patients and evaluated the obstetric history, the interval between pessary placement and delivery, gestational age at delivery, the neonatal outcome and the number of days of maternal and neonatal admission.

Results: Among the study group of 21 patients, 20 patients had a singleton and one had a dichorionic/diamniotic twin pregnancy. At insertion, the mean gestational age was $17+2(10+5-24+0)$ weeks and the mean cervical length was 19 (436) $\mathrm{mm}$. Six patients presented with funneling at insertion with a mean funneling width of 19.7 (10-38) $\mathrm{mm}$ and funneling length of 19.9 (1037) $\mathrm{mm}$. Five patients had already lost at least one child due to early spontaneous preterm birth and another five had at least one previous abortion, who have now delivered beyond 34 weeks. The mean gestational age at delivery was 38 $(31+1-41+0)$ gestational weeks and the mean interval between insertion and delivery was 145 (87-182) days.

Conclusion: Our findings suggest a beneficial effect of an early pessary placement for patients at high-risk for preterm birth due to conization.

\section{Zusammenfassung \\ $\nabla$}

Ziel: Schwangere Patientinnen nach Konisation haben ein erhöhtes Risiko für eine Frühgeburt. Das Ziel der vorliegenden Studie war die prospektive Beobachtung einer Kohorte von Schwangerschaften nach einer oder mehreren Konisationen und früher Behandlung mit einem zervikalen Pessar.

Methoden: In dieser Pilotstudie wurden insgesamt 21 Patientinnen rekrutiert. Es wurden die geburtshilfliche Anamnese, die Zervixlänge und die Zervixstruktur (Funneling) mithilfe transvaginaler Sonografie, die Prolongation der Schwangerschaft, das Gestationsalter bei der Entbindung, sowie das neonatale Outcome und die Tage des Aufenthalts von Müttern und Kindern erfasst.

Ergebnisse: Das Kollektiv umfasste 21 Patientinnen, 20 Patientinnen hatten eine Einlings- und 1 Patientin hatte eine dichoriale/diamniale Zwillingsschwangerschaft. Beim Einlegen des Pessars betrug das mittlere Gestationsalter $17+2(10+$ 5-24+0) Schwangerschaftswochen (SSW) und die mittlere Zervixlänge 19 (4-36) $\mathrm{mm}$. Sechs Patientinnen zeigten eine Trichterbildung bereits beim Einlegen des Pessars mit einer mittleren Breite von 19,7 (10-38) mm und einer mittleren Länge von 19,9 (10-37) mm. Fünf Patientinnen hatten bereits ein Kind aufgrund von Frühgeburtlichkeit verloren und 5 weitere Patientinnen hatten mindestens eine Fehlgeburt in der Anamnese, welche in der aktuellen Schwangerschaft nach der 34. SSW entbunden haben. Das mittlere Gestationsalter bei Entbindung war $38(31+1-$ $41+0)$ SSW und die mittlere Zeit zwischen Einlegen des Pessars und Entbindung betrug 145 (87-182) Tage.

Schlussfolgerung: Unsere Ergebnisse zeigten einen nützlichen Effekt der frühzeitigen Behandlung mit Pessar für Risikoschwangerschaften nach Konisation. 


\section{Introduction}

$\nabla$

A history with one or more surgical conizations increases the risk of spontaneous preterm birth (SPTB). Ortoft et al. investigated the outcome in patients who had undergone a surgical conization. They reported a 2.8-fold increased perinatal death rate, an almost 5 -fold risk for SPTB after a single and a 10 -fold risk for SPTB after two cone biopsies in subsequent pregnancies [1]. The proportion of muscular and collagen content of the cervix varies [2-4]. Smooth muscle tissue decreases from the region of the internal (29\%) towards the external os (6\%) [2]. Consequently, a cold knife cone biopsy removes the collagen-rich part of the cervix. Therefore, the etiology of cervical shortening after cone biopsies is different compared to "only" precocious cervical ripening. Clinical findings and more recent proteomic studies have suggested that the cervical mucus plug plays an important role in the maintenance of pregnancy by protecting the intrauterine cavity from ascending infection $[5,6]$. Since the remaining endocervical canal containing cervical mucus is short, this may represent an additional risk for ascending infections. Finally, a progressive opening of the internal os may lead to cervical dilatation and preterm rupture of membranes in patients with or without a history of conization, but dilatation may occur earlier in patients with a history of conization.

Abdominal cerclage has been proposed as an option in patients where the cervix had been completely removed either by trachelectomy or by repetitive conizations [7]. Up to now, both a prophylactic and an emergency cerclage have failed to reduce the rate of SPTB in patients with a history of conization [8-11]. In patients with cervical shortening but enough cervical tissue to be surrounded by a pessary, abdominal cerclage might be avoided [13].

Recently, Goya et al. have shown that the application of an Arabin cervical pessary, when applied in mid trimester after detecting a short cervical length (CL) in a screening population can significantly reduce the rate of poor composite neonatal outcome in singleton pregnancies by prolonging pregnancy [14]. Encouraged by previous studies [15] in different risk settings as summarized recently [16], we evaluated the course of pregnancies with cervical shortening after at least one conization and early treatment with a cervical pessary.

The primary aim of this descriptive study was to investigate the mean interval between pessary placement and delivery in this high-risk group of patients with short cervix and former conization. Apart from this, we regularly followed the cervical length and report on the mode of delivery.

\section{Methods \\ $\nabla$}

\section{Patient recruitment}

Patients with a history of late abortion, early SPTB and/or a conization with significant tissue reduction are usually referred to our preterm birth clinic in the first and second trimester or at least when first symptoms of threatening SPTB are present. All pregnant women transferred to our unit due to at least one cold knife conization between 2010 and 2013 were examined by both speculum investigation and transvaginal sonography (TVS), whereby the CL was detected as described by lams et al. [17]. At least 3 measurements of the CL were performed during a 3-minute interval and the shortest value was obtained for the calculations. All patients had undergone combined first trimester screening with sonographic markers according to the Fetal Medicine Foundation (FMF) to exclude fetuses at risk for chromosomal abnormalities [18]. This patient group received no additional progesteron, in order to avoid further treatment bias.

\section{Clinical assessment and pessary placement}

Twenty-one patients were included in the study when the cervico-isthmic complex in the first trimester, correlating to the inner $\mathrm{CL}$ in the second trimester, was below the 10th centile according to Salomon [19] and when there was enough remaining cervical tissue so that a pessary with an inner diameter of $32 \mathrm{~mm}$ could be fixed around the cervix without the risk of displacement. The patients were informed about the up-to-date knowledge of success rates of a cerclage and the pioneer treatment of pessary treatment for this indication, which was approved by our ethics committee. Both a speculum examination and TVS were used for indication and a control examination directly after the first insertion of the pessary (Arabin pessary, approved in Europe for the indication to prevent SPTB: CE0482, MED/CERT ISO 9003/EN 46003). When patients presented in the first trimester, a pessary of $32 \mathrm{~mm}$ (upper diameter), $17 \mathrm{~mm}$ (height) and 65 or $70 \mathrm{~mm}$ (lower diameter, primi-or multiparous women) was chosen, during the second trimester only the height was changed to $21 \mathrm{~mm}$ [16]. It has been demonstrated that even the pessary of $25 \mathrm{~mm}$ height was not limiting sexual intercourse in the pessary arm as opposed to controls in patients of the trial by Goya et al. [14] (personal communication). Patients with a pessary of only $17 \mathrm{~mm}$ have even less complaints of discharge or mechanical disturbance.

Patients were followed in our unit whereby the CL was examined as described previously [20]. Only two specialists were involved in the indication, application, surveillance and follow-up.

\section{Statistical analysis}

After delivery, we evaluated the mean interval between pessary placement and delivery, the neonatal outcome as well as the total days of hospital admission. Statistical analysis was performed by Excel (Office Mac 2011). O Table 1 demonstrates the history, result of TVS before therapy, gestational age at insertion, the course and outcome of the pregnancy.

\section{Details of ethics approval}

The ethics committee of the University Hospital of Marburg gave permission to perform the study as part of a clinical approach, which had already been accepted as a clinical management in patients at risk for preterm delivery.

\section{Results \\ $\nabla$}

Baseline characteristics of the patient population

Our study population included 20 singleton pregnancies (case 1$20)$ and 1 dichorionic-diamniotic (DCDA) twin pregnancy (case 21). Data of our study group are shown in Table 1.

All patients had a history of at least one conization before the current pregnancy. Median interval between the first conization and the index pregnancy was 4.5 (1-9) years. Indication for the conization was a repetitive Papanicolaou smear test of III D or worse, following the current German guideline of 2014 [21]. Histopathologic examination had shown that 4/21 patients had a mild cervical intraepithelial neoplasia (CIN I), another 4/21 a moderate CIN (CIN II) and 10/21 severe dysplasia (CIN III). The remaining 


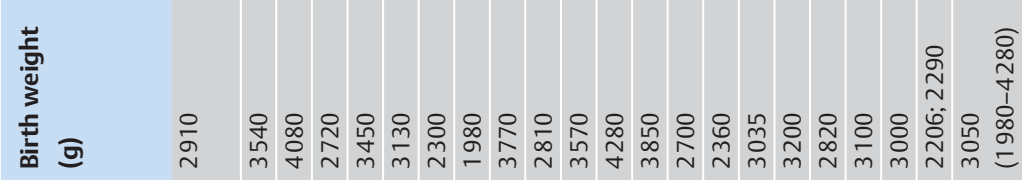

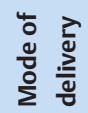

$\cup>\cup \cup>>>>\cup \cup>>\cup>>>>>>\cup$

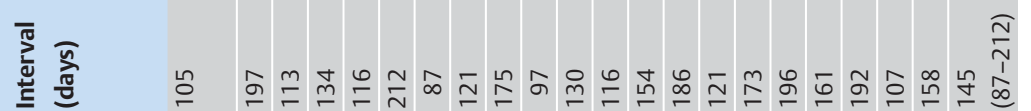
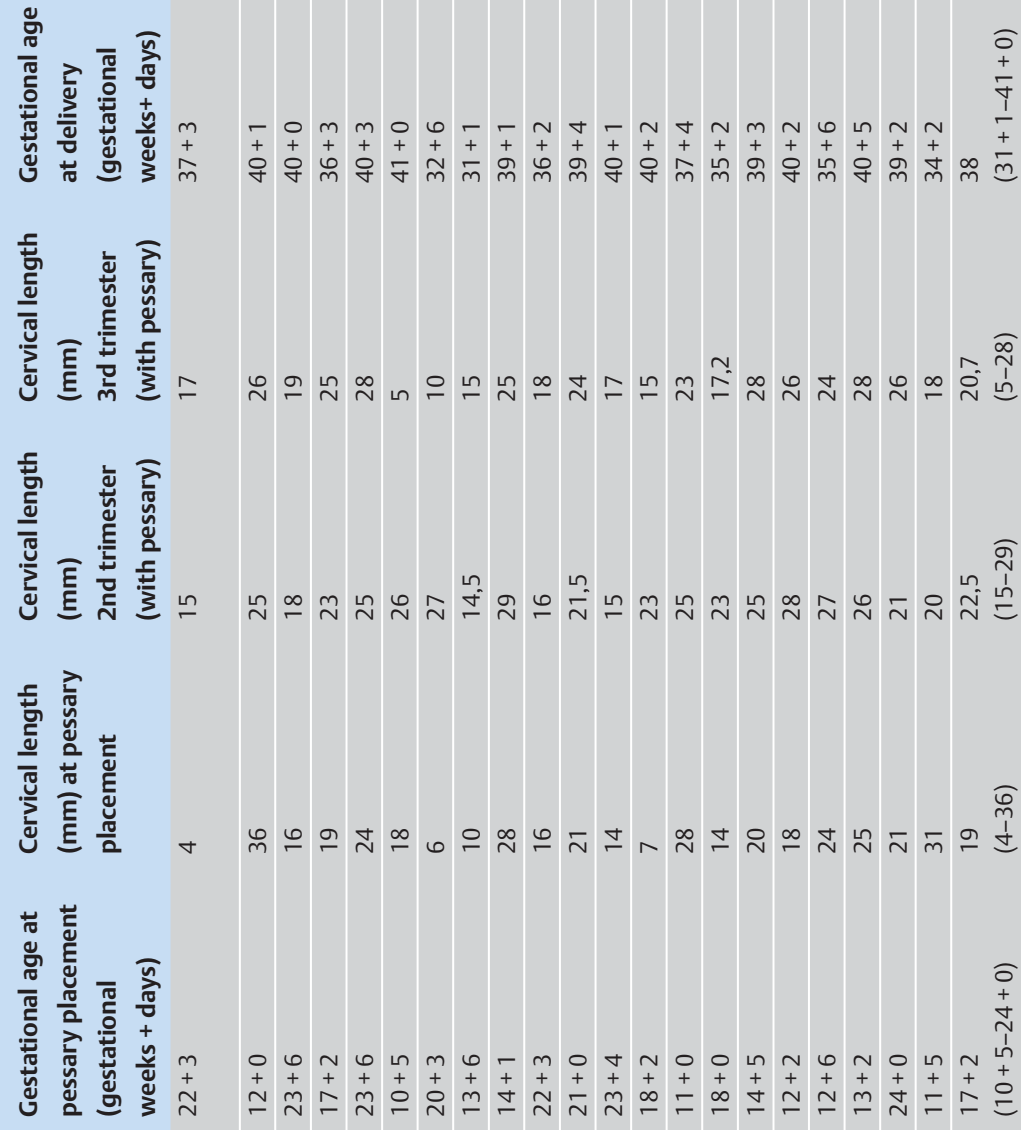

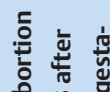

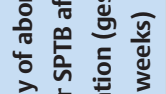

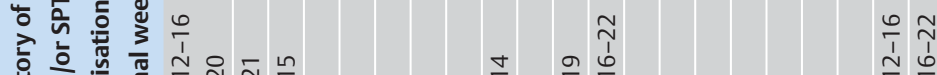

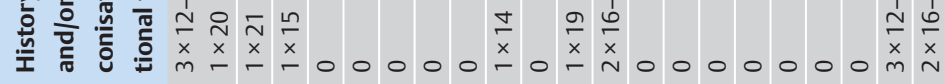

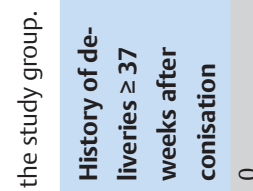

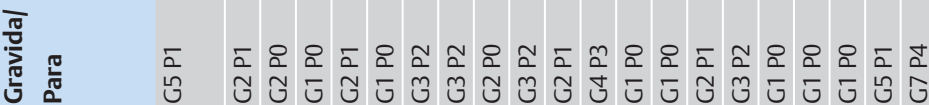

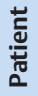

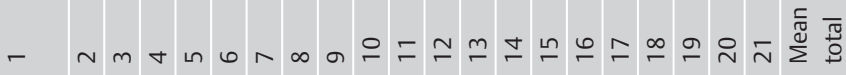

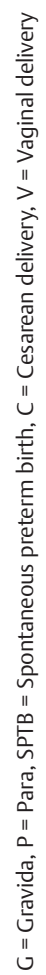




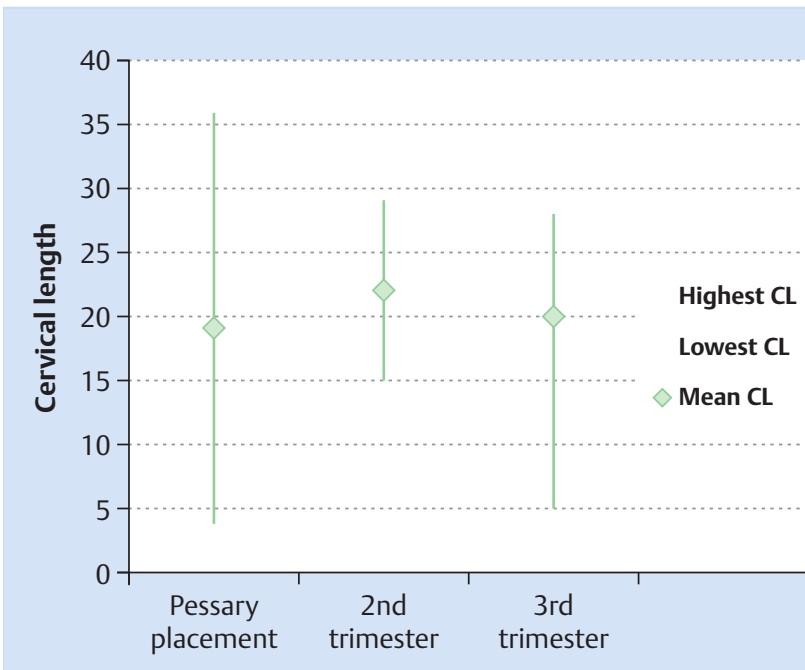

Fig. 1 Mean values of the cervical length (CL) at pessary placement, and during subsequent measurements in the second and third trimester $(\mathrm{n}=21)$. The mean $\mathrm{CL}$ changed from $19(4-36) \mathrm{mm}$ at pessary placement to $22.5(15-29) \mathrm{mm}$ and $20.7(5-28) \mathrm{mm}$ in the second and third trimester respectively. The elongation of the $\mathrm{CL}$ resulted into a clinically important interval between placement and delivery.

3/21 patients had a chronic cervicitis. To better scrutinize the invasive nature of a cone biopsy, the dimensions of the removed tissue were retrospectively evaluated. The dimensions ranged between $1.3 \times 1.3 \times 0.2 \mathrm{~cm}$ and $4 \times 2.5 \times 0.3 \mathrm{~cm}$. In two patients a second conization was indicated because of infested dysplastic cells on the edge of the cone.

In the index pregnancy, the mean gestational age at TVS indicating a pessary insertion was $17+2(10+5-24+0)$ gestational weeks and the mean cervical length (CL) was 19 (4-36) mm. Six patients presented with funneling at insertion with a mean proportion of funneling width of 19.7 (10-38) $\mathrm{mm}$ and funneling length of 19.9 (10-37) $\mathrm{mm}$.

Five patients (24\%) had already lost at least one child due to early SPTB before viability after conization, whereby $3 / 21$ patients (14\%) - among them the patient with DCDA twins - had already lost 2 children between 16 and 22 weeks due to cervical insufficiency. All of these patients delivered beyond 34 weeks, the patient with the twin pregnancy underwent a primary Caesarean delivery due to preeclampsia at $34+2$ gestational weeks. Five patients (24\%) had a history with previous abortion. Seven/21 patients (33\%) were primiparous. $\odot$ Fig. 1 demonstrates the mean course of CL during the course of pregnancy as calculated from - Table 1.

\section{Outcome of the patient population}

The mean gestational age at delivery was $38+0(31+1-41+0)$ weeks and the mean interval between insertion and delivery was 145 (87-182) days. The mean duration of admission during pregnancy was $11(0-28)$ days. Indications for admission were intermediate premature contractions $(n=5)$, preeclampsia $(n=2)$, suspicion of intrauterine growth retardation $(n=1)$ or intermediate feelings of insecurity at early gestational age combined with a long distance from home in patients with previous immature birth $(n=5)$.

Indications for a Caesarean delivery included pathologic fetal heart rate (FHR) tracing (case 1), prolonged labour (case 3, 4,
14), severe condylomata accuminata (case 9), breech presentation (case 10), and preeclampsia in a twin gestation (case 21). Immediate neonatal outcome of all newborns was uneventful, 20/21 newborns were discharged with their mothers 2-5 days after delivery, only one infant (case 3) was admitted to our neonatal unit for 10 days due to prematurity, but had no symptoms of respiratory distress syndrome, brain injury, neonatal sepsis or necrotizing enterocolitis.

\section{Discussion}

The results of the present study indicate that treatment with a cervical pessary leads to a clinically important elongation of the cervival length, which resulted in a mean interval between pessary insertion and delivery of 145 (87-182) days. As such, we report a mean gestational age at delivery of $38+0(31+1-41+0)$ weeks. The mean duration of admission during pregnancy was 11 (0-28) days.

In 2012, Greco et al. have shown that prediction of SPTB is feasible in the first trimester [22]. Between 11 and 13 weeks, the authors measured the linear distance of the glandular area of the endocervical canal and the cervico-isthmic complex in singleton pregnancies. There are still discrepant views how to measure the $\mathrm{CL}$ in both the first and the second trimester. Most investigators still use the "standard technique" described by Iams et al. [17], which correlates to the cervico-isthmic complex in the first trimester. Vayssiere et al. used this technique in twin gestations [23], according to the author's opinion the inter-operator variance is less compared to the technique of measuring only the part bordered by the endocervical mucosa (personal communication). In any case, normal values of both techniques differ since the absolute values are higher when using the standard technique. Therefore, the criteria of cervical measurements have to be strictly defined when starting or comparing multicentre trials. Castanon et al. explored the association of conization and SPTB in a cohort of patients undergoing colposcopy in 12 National Health Service hospitals in Great Britain [26]. The authors reported a SPTB-rate of $9.0 \%$ after a simple punch biopsy during colposcopy or a rate of $9.4 \%$ after a superficial conization respectively (RR $1.41, \mathrm{p}=0.03$ ). In comparison, the average SPTB rate in England in the past decade was $6.7 \%$. Interestingly, the proportion of SPTB varied widely by hospital from $6.2-15.6 \%$ according to the size of the average cone. These data are consistent with the study of Poon et al. who reported a significant association between large loop excision procedure (LEEP) and the risk of SPTB, even after adjustment of maternal risk factors [27]. In our population, gynecologists only performed the cold knife conization. In contrast to the cold-knife conization, LEEP helps to conserve the cervical stroma volume. Patient selection for cold-knife conization favors those at highest risk for invasive cancer including cervical cytology suspicious for invasive cancer, patients older than 35 years with CIN III or carcinoma in situ, large high-grade lesions, and biopsies showing endocervical adenocarcinoma [28].

The "Arabin" cervical pessary was already demonstrated in German book chapters 30 years ago [16], but the first pilot study using TVS of the CL as a reference in singleton and twin pregnancies was published just 10 years ago [29]. In 2012, Goya et al. performed the first randomised trial using TVS and recruiting the planned sample size of 385 singleton pregnancies with a CL $\leq 25 \mathrm{~mm}$ at $18-22$ gestational weeks for randomisation. Thereby the rate of SPTB before 34 weeks of gestation was reduced from 
27 to $6 \%$, as well as the rate of SPTB before 32 and 28 weeks. The rate of adverse neonatal outcome was significantly better in the pessary compared to the control group (RR: $0.2 ; 95 \% \mathrm{CI} 0.1$ to 0.4) [14]. However, patients with a history of cone biopsy had been excluded from this study. Notably, cervical pessaries have not proven to be efficient in the preventing setting, when the $\mathrm{CL}$ is longer than $25 \mathrm{~mm}$ [30]. We have previously shown that abdominal cerclage was even successful in preventing early SPTB in a twin pregnancy with complete removal of cervical tissue [12]. However, abdominal cerclage is invasive and requires expertise of the surgeon [24]. As such, in patients with a history of a conization both a prophylactic and a "therapeutic" cerclage in patients with cervical shortening have failed to effectively prevent SPTB [8-11,25].

In 2013, the so-called Pro-Twin trial recruited 813 women with multiple pregnancies in the Netherlands [31]. Patients were randomised to either pessary or expectant management between 16 and 20 weeks. Although there was no difference in the primary outcome of all twin pregnancies, composite poor neonatal outcome (perinatal death or severe morbidity), was significantly lower in a prespecified subgroup of women who had a CL below 25 th percentile $(<38 \mathrm{~mm})$ at $16-20$ gestational weeks and a pessary treatment. A study performed by the FMF did not yet find a positive effect of the pessary in twin gestations although the data are not yet published. In both studies, the compliance and possibly the results could have been improved by teaching, patient information or audit procedures [27]. Another study, which has not yet been published, has found a significant reduction in SPTB before 34 gestational weeks in twin pregnancies randomized in the second trimester when the CL was $<25 \mathrm{~mm}$ (Carreras, personal communication). In the only patient with a twin pregnancy in our pilot study, the pessary was placed as early as possible, e.g. at $11+5$ gestational weeks. This patient had already 2 abortions before the conization and had lost 2 children between 16 and 22 gestational weeks due to cervical insufficiency after the conization. The CL at pessary placement at $11+5$ weeks was $31 \mathrm{~mm}$. This twin pregnancy was prolonged up to $34+2$ gestational weeks, when a Caesarean delivery was indicated due to preeclampsia.

Interestingly, the mean CL increased during the course of pregnancy in some patients after pessary insertion from the first to the second trimester ( Table 1, Fig. 1). Clinical examinations have suggested that the longer the pessary stays in place, the greater is the chance that the cervix develops some degree of thickening or edema - at least in some patients. More objectively, this has now been confirmed using Magnetic Resonance Tomography (MRI) by Cannie et al. demonstrating that the pessary changes the inclination of the cervical canal relative to the uterus and that this persisted as long as the pessary remained in situ [32]. In addition, the authors demonstrated an elongation and even disappearance of funneling in some patients. This might explain that direct pressure on the membranes and the cervical integrity at the level of internal cervical os is reduced, which might be more crucial in patients with a history of a conization.

\section{Strengths and limitations}

Our pilot study has limitations. Since data were only recruited within one center, the number of patients is too small to make final conclusions about the effects of early pessary treatment in patients with a history of conization and a short CL early in pregnancy. All patients were referrals, which might have created a selection bias and in addition, TVS was not performed in all patients with a history of conization at a pre-defined gestational age what should be done in future trials. Furthermore, the descriptive nature of the study did not allow us to compare our results with a control group. Therefore, it is not possible to make conclusions, how the pregnancy outcome would be, without any intervention.

The strength of our pilot study is that vaginal cerclage has not been shown to be effective, the value of progestagens not (yet) been evaluated in this pre-specified subgroup and that the cervical pessary might be an alternative as suggested by the fair outcome even in patients who had a history of previous late miscarriages. Nevertheless, therapeutic negligence, e.g. not to offer any therapeutic option in patients who have already lost a child or are obviously at high risk to loose a child may be difficult for obstetricians in charge.

\section{Conclusion}

Our observational findings from this pilot study suggest that the cervical pessary leads to a clinically important long interval between pessary insertion and delivery, does not do harm and as already suggested for twin pregnancies with a short cervix might be a cost-effective and non-invasive option for patients with a history of conization $[33,34]$. The results in those few patients who had already lost children due to cervical insufficiency and now have been treated before 12 gestational weeks let us speculate that some effects of early cervical pessary treatment might be beneficial. Further prospective randomized trials, recruiting patients before 20 weeks of gestation are neccessary.

As mentioned previously, "the best answers to clinical problems will come from large international collaboration" [16].

\section{Acknowledgements}

\section{$\nabla$}

The authors thank the study participants for their contribution to clinical research.

\section{Contribution to Authorship \\ $\nabla$}

IK and BA conceived the study, participated in its design and coordination, helped to draft the manuscript and made substantial contributions to analysis and interpretation of the data. RK and NS participated in the design of the study and made substantial contributions to acquisition of data. All authors read and approved the final manuscript.

Funding: Nil

\section{Conflict of Interest}

The senior author Prof. Birgit Arabin has a direct ownership interest in the company that manufactures pessaries including those used in the study. The company is privately held and the profit is used to support the Clara Angela Foundation for Research and Development. The other authors have no conflict of interests. 


\section{References}

1 Ortoft G, Henriksen T, Hansen E et al. After conisation of the cervix, the perinatal mortality as a result of preterm delivery increases in subsequent pregnancy. BJOG 2010; 117: 258-267

2 Danforth $D N$. The distribution and functional activity of the cervical musculature. Am J Obstet Gynecol 1954; 68: 1261-1271

3 Danforth DN. The fibrous nature of the human cervix, and its relation to the isthmic segment in gravid and nongravid uteri. Am J Obstet Gynecol 1947; 53: 541-560

4 Danforth DN, Buckingham JC, Roddick JW jr. Connective tissue changes incident to cervical effacement. Am J Obstet Gynecol 1960; 80: 939945

5 Sieroszewski P, Jasinski A, Perenc $M$ et al. The Arabin pessary for the treatment of threatened mid-trimester miscarriage or premature labour and miscarriage: a case series. J Matern Fetal Med 2009; 22: 469-472

6 Kimber-Trojnar Z, Patro-Malysza J, Leszczynska-Gorzelak B et al. Pessary use for the treatment of cervical incompetence and prevention of preterm labour. J Matern Fetal Med 2010; 23: 1493-1499

7 Lotgering FK. Clinical aspects of cervical insufficiency. BMC Pregnancy Childbirth 2007; 7 (Suppl. 1): S17

8 Berghella V, Odibo AO, To MS et al. Cerclage for short cervix on ultrasonography: meta-analysis of trials using individual patient-level data. Obstet Gynecol 2005; 106: 181-189

9 Lee SM, Jun JK. Prediction and prevention of preterm birth after cervical conization. J Gynecol Oncol 2010; 21: 207-208

10 Zeisler H, Joura EA, Bancher-Todesca D et al. Prophylactic cerclage in pregnancy. Effect in women with a history of conization. J Reprod Med 1997; 42: 390-392

11 Fox NS, Gelber SE, Kalish RB et al. History-indicated cerclage: practice patterns of maternal-fetal medicine specialists in the USA. J Perinat Med 2008; 36: 513-517

12 Kyvernitakis I, Lotgering F, Arabin B. Abdominal cerclage in twin pregnancy after radical surgical conization. Case Rep Obstet Gynecol 2014; 2014: 519826

13 David $M$, Jorde A. [Conization and pregnancy-an analysis of various therapeutic measures for the prevention of premature labor]. Zentralbl Gynakol 1991; 113: 1304-1312

14 Goya M, Pratcorona L, Merced C et al. Cervical pessary in pregnant women with a short cervix (PECEP): an open-label randomised controlled trial. Lancet 2012; 379: 1800-1806

15 Abdel-Aleem H, Shaaban OM, Abdel-Aleem MA. Cervical pessary for preventing preterm birth. Cochrane Database Syst Rev 2013; 5: CD007873

16 Arabin B, Alfirevic Z. Cervical pessaries for prevention of spontaneous preterm birth: past, present and future. Ultrasound Obstet Gynecol 2013; 42: 390-399

17 Iams JD, Goldenberg RL, Meis PJ et al. The length of the cervix and the risk of spontaneous premature delivery. National Institute of Child Health and Human Development Maternal Fetal Medicine Unit Network. N Engl J Med 1996; 334: 567-572

18 Wright D, Spencer K, Kagan KK et al. First-trimester combined screening for trisomy 21 at 7-14 weeks' gestation. Ultrasound Obstet Gynecol 2010; 36: 404-411
19 Salomon LJ, Diaz-Garcia C, Bernard JP et al. Reference range for cervical length throughout pregnancy: non-parametric LMS-based model applied to a large sample. Ultrasound Obstet Gynecol 2009; 33: 459-464

20 Goya M, Pratcorona L, Higueras $T$ et al. Sonographic cervical length measurement in pregnant women with a cervical pessary. Ultrasound Obstet Gynecol 2011; 38: 205-209

21 Beckmann MW, Mallmann P; Uterus Commission of the Gynecological Oncology Working Group (AGO). Interdisciplinary S2k guideline on the diagnosis and treatment of cervical carcinoma. J Cancer Res Clin Oncol 2009; 135: 1197-1206

22 Greco E, Gupta R, Syngelaki A et al. First-trimester screening for spontaneous preterm delivery with maternal characteristics and cervical length. Fetal Diagn Ther 2012; 31: 154-161

23 Vayssiere C, Favre R, Audibert F et al. Cervical length and funneling at 22 and 27 weeks to predict spontaneous birth before 32 weeks in twin pregnancies: a French prospective multicenter study. Am J Obstet Gynecol 2002; 187: 1596-1604

24 Quaas L, Hillemanns HG, du Bois A et al. Das Arabin-Cerclage-PessarEine Alternative zur operativen Cerclage. Geburtsh Frauenheilk 1990; 50: 429-433

$25 \mathrm{Nam} \mathrm{KH,} \mathrm{Kwon} \mathrm{JY,} \mathrm{Kim} \mathrm{YH} \mathrm{et} \mathrm{al.} \mathrm{Pregnancy} \mathrm{outcome} \mathrm{after} \mathrm{cervical} \mathrm{con-}$ ization: risk factors for preterm delivery and the efficacy of prophylactic cerclage. J Gynecol Oncol 2010; 21: 225-229

26 Castanon A, Brocklehurst P, Evans $H$ et al. Risk of preterm birth after treatment for cervical intraepithelial neoplasia among women attending colposcopy in England: retrospective-prospective cohort study. BMJ 2012; 345: e5174

27 Poon CY, Edwards JM, Joshi S et al. Optimization of myocardial deformation imaging in term and preterm infants. Eur J Echocardiogr 2011; 12 : 247-254

28 Schorge JO, Williams JW. Williams Gynecology. New York: McGraw-Hill Medical; 2008

29 Arabin B, Halbesma JR, Vork $F$ et al. Is treatment with vaginal pessaries an option in patients with a sonographically detected short cervix? J Perinat Med 2003; 31: 122-133

30 Hui SY, Chor CM, Lau TK et al. Cerclage pessary for preventing preterm birth in women with a singleton pregnancy and a short cervix at 20 to 24 weeks: a randomized controlled trial. Am J Perinatol 2013; 30: 283288

31 Liem S, Schuit E, Hegeman $M$ et al. Cervical pessaries for prevention of preterm birth in women with a multiple pregnancy (ProTWIN): a multicentre, open-label randomised controlled trial. Lancet 2013; 382: 1341-1349

32 Cannie MM, Dobrescu O, Gucciardo L et al. Arabin cervical pessary in women at high risk of preterm birth: a magnetic resonance imaging observational follow-up study. Ultrasound Obstet Gynecol 2013; 42: 426-433

33 Hildebrandt T, Kraml F, Wagner S et al. Impact of patient and procedure mix on finances of perinatal centres - theoretical models for economic strategies in perinatal centres. Geburtsh Frauenheilk 2013; 73: 783791

34 Liem SM, van Baaren GJ, Delemarre FM et al. Economic analysis of use of pessary to prevent preterm birth in women with multiple pregnancy (ProTWIN trial). Ultrasound Obstet Gynecol 2014; 44: 338-345 